\title{
COVID-19 e suas correlações com as doenças reumáticas em crianças
}

\author{
Daniela Gerent Petry Piotto ${ }^{1}$, Paulo Roberto Stocco Romanelli ${ }^{2}$ \\ DOI: https://doi.org/10.46833/reumatologiasp.2020.19.3.36-42
}

\begin{abstract}
Resumo A pandemia COVID-19 tem implicações mundiais importantes, principalmente em pacientes acima dos 60 anos de idade e com comorbidades, dentre estas as doenças autoimunes, como as doenças reumáticas, dentre aquelas que supostamente teriam maior probabilidade tanto de adoecimento quanto de desenvolvimento das formas graves dessa virose, particularmente nos pacientes submetidos a uma variedade de terapias imunossupressoras. Notou-se que crianças e adolescentes são um grupo que pouco adoecem ou desenvolvem as formas graves da COVID-19. Vários motivos foram imputados para tentar explicar este menor comprometimento clínico nesta faixa etária. Além do mais, a grande maioria destes jovens, quando infectados pelo SARS-CoV-2, apresentam sintomas frustros ou de pouca intensidade. Quando pequena parte deste grupo etário desenvolve as formas moderadas, fazem-no como uma síndrome gripal; já os mais graves, como a síndrome respiratória aguda grave. Uma pequena parcela das crianças mais velhas desenvolve uma grande liberação de citocinas, culminando numa síndrome inflamatória multissistêmica, muito semelhante clinicamente à síndrome de Kawasaki, embora esta última tenha preferência por crianças em idade bem mais precoce. Alguns medicamentos utilizados no tratamento das doenças da reumatologia pediátrica estão sendo usados nas formas graves da COVID-19, pelo potencial benefício de interferir drasticamente na resposta inflamatória. Muitas semelhanças foram encontradas entre as prováveis patogenias, características clinicolaboratoriais e tratamentos entre as doenças reumáticas e a COVID-19, sobretudo nas formas graves desta última, o que faz com que os reumatologistas pediátricos estejam bem atualizados e capacitados também para os cuidados dos jovens pacientes com todas as formas da COVID-19.
\end{abstract}

Unitermos COVID-19. Crianças e adolescentes. Doenças reumáticas na infância. Kawasaki. Síndrome inflamatória multissistêmica pediátrica.

\section{INTRODUÇÃO}

Desde o início da epidemia causada pelo novo coronavírus SARS-Cov-2 ("Severe Acute Respiratory Syndrome Coronavirus-2”) no final de 2019 na China, até a decretação de pandemia pela Organização Mundial da Saúde (OMS) em março de 2020, então designada como COVID-19, teve como característica, em todas as partes do mundo, o baixo acometimento clínico da faixa etária pediátrica quando comparada aos adultos, sobretudo aqueles acima dos 60 anos de idade. Dados de vários países mos-
1. Médica reumatologista pediátrica. Professora afiliada/visitante do Departamento de Pediatria da Universidade Federal de São Paulo (Unifesp). Doutorado em Pediatria e Ciências Aplicadas à Pediatria pela Unifesp. Membro do Departamento Científico de Reumatologia da Sociedade de Pediatria de São Paulo e de Reumatologia Pediátrica da Sociedade Paulista de Reumatologia, São Paulo-SP, Brasil.

2. Médico reumatologista e reumatologista pediátrico. Membro do Conselho Científico da Sociedade Paulista de Reumatologia, Departamentos Científicos de Reumatologia da Sociedade Brasileira de Pediatria, da Sociedade de Pediatria de São Paulo e de Reumatologia Pediátrica da Sociedade Paulista de Reumatologia.
Reumatologista do Núcleo Avançado de Reumatologia (NARe) do Hospital Sírio-Libanês, São Paulo-SP, Brasil.

Correspondência: Dra. Daniela Piotto, e-mail: danielapetry@gmail.com. Como citar este artigo: Piotto DGP, Romanelli PRS. COVID-19 e suas correlações com as doenças reumáticas em crianças. Rev Paul Reumatol. 2020 jul-set;19(3):36-42. DOI: https://doi.org/10.46833/ reumatologiasp.2020.19.3.36-42.

Os autores não contaram com apoio financeiro.

Os autores declaram não ter interesses associativos, comerciais, de propriedade ou financeiros que representem conflito de interesse nos produtos e empresas descritos neste artigo. 
tram que menos de $2 \%$ dos casos sintomáticos ocorreram em crianças e adolescentes, sendo a maioria com um curso clínico mais leve da doença, com baixas taxas de hospitalização (0,6$20 \%)$ e mortalidade $(0-4 \%)^{1-5}$. As crianças com comorbidades prévias apresentaram maior gravidade ${ }^{5,6}$.

Os motivos inferidos pelos quais as crianças adoecem menos que os adultos, embora apresentem sintomas clínicos semelhantes, mas geralmente em menor grau de intensidade, podem ser explicados por algumas hipóteses, dentre elas:

- Presença em menor grau dos receptores da enzima conversora de angiotensina 2 (ACE2), além de ainda serem imaturos, nas células tipo 1 e 2 do epitélio respiratório das crianças, necessário como porta de entrada no organismo hospedeiro para a posterior replicação viral. Há uma maior predominância desses receptores no sexo masculino?

- Diferenças nas respostas imunes das crianças que reagiriam ao vírus com mais vigor através de uma imunidade inata e com resposta mais eficiente das células $\mathrm{T}$, que impediria a replicação do vírus nas células, diferentemente dos adultos, onde a imunidade adquirida mais exacerbada levaria a uma “tempestade de citocinas”, consequentemente com maiores danos teciduais ${ }^{8-9}$.

- Maior integridade do endotélio dos vasos sanguíneos arteriais nas crianças em relação aos adultos, evitando assim a formação de coágulos a partir da agressão viral ${ }^{10}$.

- Possível imunidade cruzada a infecções por outras cepas de coronavírus, que causam resfriados comuns, podendo-lhes conferir alguma memória imunológica ao SARS-CoV-2 ${ }^{11}$.

- Possível efeito protetor inespecífico da vacina BCG na COVID-19. Sabe-se que a vacina BCG induz mudanças epigenéticas em monócitos humanos que codificam citocinas pró-inflamatórias, como interleucina 6 (IL-6) e TNF-a (fator de necrose tumoral) ${ }^{12}$. Isso causa uma maior atividade na resposta imune inata após uma reinfecção, o que poderia contribuir para a eliminação efetiva do vírus no caso da COVID-19. A taxa de mortalidade foi significativamente menor em países com programas de vacinação $\mathrm{BCG}^{13}$.

\section{EPIDEMIOLOGIA}

As crianças em geral são expostas a partir do contato doméstico com caso índice familiar, embora possa haver também contatos externos, como nas escolas e demais locais ${ }^{14}$. Atualmente, até que ponto as crianças contribuem para a transmissão não é totalmente compreendido. Crianças também podem transmitir o vírus em menor proporção que os adultos e sua transmissibilidade aumenta quanto maior for a idade da criança ${ }^{15}$.

Ao que tudo indica, a necessidade de hospitalização de crianças e adolescentes pela gravidade do quadro clínico da COVID-19 parece bem menor do que nos adultos. Segundo o Centro de Controle e Prevenção de Doenças (CDC) americano, a taxa de hospitalização encontra-se em torno de 2,5-4,1\%, e as que necessitam de internação em UTI situam-se em menos de $1 \%{ }^{2}$. Tais situações ocorrem principalmente nas crianças e adolescentes que possuem comorbidades associadas, como, por exemplo, imunossupressão, doenças respiratórias crônicas, doenças cardiovasculares, malformações congênitas complexas, síndrome de Down, diabetes mellitus tipo 1 e anemia falciforme ${ }^{16,17}$. Estes dados foram comprovadamente semelhantes em populações estudadas nos EUA, China e Itália²-5,18,19.

Tal característica parece variar, conforme diversos estudos, de 1-6\% dos casos confirmados laboratorialmente acometendo crianças até 18 anos de idade ${ }^{4,20}$. Num estudo multicêntrico europeu foi encontrada a seguinte distribuição por faixa etária: $7 \%$ em menores de 1 mês; $22 \%$ entre 1 mês e 1 ano; $10 \%$ entre 1-2 anos; $11 \%$ entre $2-5$ anos; $16 \%$ entre $5-10$ anos; $34 \%$ entre 10-18 anos $^{21}$.

Para a população brasileira, o indicador oficial utilizado para investigar casos hospitalizados e óbitos (independente de hospitalização) por síndrome respiratória aguda grave (SRAG), que contempla os casos de infecção pelo SARS-CoV2, é o Sistema de Vigilância Epidemiológica da Gripe (SIVEP Gripe) ${ }^{22}$.

Segundo o boletim epidemiológico emitido oficialmente, até a semana epidemiológica 29 (de 12 a 18/07/2020), foram notificados 33.866 casos hospitalizados por SRAG na faixa de idade de 0-18 anos $^{22}$. Destes, 4.670 casos (13,7\%) foram confirmados por COVID-19, dos quais 2.393 (52\%) ocorreram em crianças de até cinco anos de idade. Em relação à mortalidade, do total, ocorreram 1.747 óbitos correspondendo a 1,5\% dos óbitos por SRAG no País, dos quais 31\% confirmados por COVID-19, 57\% do tipo não especificado e 6,4\% permaneciam em investigação etiológica. Apesar de não haver dados disponíveis quanto às características clinicoepidemiológicas destes óbitos, a faixa etária de até 1 ano de idade foi responsável pelo maior número de casos e óbitos confirmados por COVID-19 por número de anos, até a data de sua publicação ${ }^{22}$. Esta situação encontra-se em concordância com as observações realizadas por Dong et al. na China, que verificaram maior probabilidade de quadros de maior gravidade em lactentes e pré-escolares ${ }^{1}$.

No Estado de São Paulo, segundo dados ainda não publicados e obtidos através de comunicação pessoal com o Centro de Vigilância Epidemiológica "Prof. Alexandre Vranjac" (CVE/SES-SP), até a data de 06/08/2020 foram registrados 35.414 casos de COVID-19 em menores de 20 anos de idade, representando 6\% do total de casos confirmados, dos quais $96 \%$ contemplam sintomas de síndrome gripal, ou seja, casos leves ou moderados, com a seguinte distribuição etária:

- Menores de 1 ano: 2.475 casos (7,0\%).

- De 1 a 4 anos: 4.835 casos (13,6\%).

- De 5 a 9 anos: 5.294 casos (15,0\%).

- De 10 a 19 anos: 22.810 casos (64,4\%).

Já com relação ao número de mortes nesta mesma população, abaixo de 20 anos de idade e no mesmo período, verificou-se um total de 87 óbitos ( $0,25 \%$ do total dos casos), dos quais $67 \%$ ocorreram na presença de comorbidades.

\section{ACHADOS CLÍNICOS}

Por não dispormos de estatísticas oficiais em nosso meio que disponibilizem os principais achados clínicos para a faixa etária pediátrica, utilizamos os encontrados pelo $\mathrm{CDC}$ americano ${ }^{20}$, que os dividem em: 
- Sintomas de 0-9 anos:

- Febre, tosse e respiração rápida - 63\%;

(febre $-46 \%$; tosse - 37\%);

- Cefaleia - 15\%;

- Diarreia-14\%;

- Rinorreia - 13\%;

- Náusea e vômito - 10\%;

- Mialgia - 10\%;

- Respiração rápida - 7\%;

- Dor abdominal - 7\%;

- Perda do olfato ou do paladar - 1\%.

- Sintomas de 10-19 anos:

- Tosse $-41 \%$;

- Cefaleia $-42 \%$;

- Febre-35\%;

- Mialgia - 30\%;

- Respiração rápida - 16\%;

- Diarreia - 14\%;

- Náusea e vômito - 10\%;

- Perda do olfato ou do paladar - 10\%;

- Rinorreia - 8\%;

- Dor abdominal - 8\%.

Segundo as definições do Ministério da Saúde, os casos suspeitos de COVID-19 devem preencher os seguintes critérios ${ }^{23}$ :

- Síndrome gripal (SG): indivíduo com quadro respiratório agudo, caracterizado por pelo menos dois dos seguintes sinais e sintomas: febre (mesmo que referida), calafrios, dor de garganta, dor de cabeça, tosse, coriza, distúrbios olfativos ou distúrbios gustativos. Observações: em crianças, além dos itens anteriores, considera-se também obstrução nasal, na ausência de outro diagnóstico específico. Na suspeita de COVID-19, a febre pode estar ausente e sintomas gastrointestinais (diarreia) podem estar presentes.

- Síndrome respiratória aguda grave (SRAG): indivíduo com SG que apresente: dispneia/desconforto respiratório OU pressão persistente no tórax OU saturação de $\mathrm{O}_{2}$ menor que 95\% em ar ambiente OU coloração azulada dos lábios ou rosto. Observações: em crianças, além dos itens anteriores, observar os batimentos de asa de nariz, cianose, tiragem intercostal, desidratação e inapetência.

Desde abril de 2020 há relatos crescentes na Europa, América do Norte, Ásia e América Latina descrevendo crianças e adolescentes com doenças inflamatórias multissistêmicas associadas à COVID-1924-28. Inicialmente foram confundidas com a síndrome de Kawasaki (SK) em suas formas completa e incompleta, mas na verdade possuem características clínicas por vezes indistinguíveis desta. Há um espectro clinicolaboratorial por vezes semelhante à SK, embora outras vezes se assemelhe à síndrome do choque tóxico, síndrome hematofagocítica linfoproliferativa, síndrome de ativação macrofágica (SAM), tendo sido denominada síndrome multissistêmica inflamatória pediátrica (SIM-P) ${ }^{29}$.

A SIM-P geralmente ocorre em crianças mais velhas, escolares e adolescentes, previamente saudáveis, com marcadores de atividade inflamatória mais exuberantes e importantes elevações dos indicadores de lesão cardíaca. A doença acontece de 2 a 4 semanas após a infecção aguda por COVID-19 ou contato confirmado, é multissistêmica envolvendo pelo menos dois órgãos e sistemas, tais como: dermatológico, gastrointestinal, cardíaco, renal, respiratório, hematológico ou neurológico ${ }^{27,28}$. Disfunção ventricular e choque cardiogênico são frequentes na SIM-P, podendo ocorrer em mais de 50\% dos pacientes ${ }^{26}$. Algumas dessas crianças podem apresentar alguma doença crônica preexistente, como neoplasias, doenças autoimunes, imunodeficiências primárias ou uso de medicamentos imunossupressores ${ }^{27-29}$.

Os achados laboratoriais incluem linfopenia, aumento de provas de atividade inflamatória (proteína C reativa, velocidade de hemossedimentação, procalcitonina, ferritina), dos indicadores sorológicos de coagulopatia (tempo de protrombina, tempo de tromboplastina parcial ativado, D-dímero) e das provas de função miocárdica [troponina, N-terminal do peptídeo natriurético tipo B (NT-proBNP)] $]^{24-29}$. Existem outras características laboratoriais importantes que diferenciam as fases agudas e críticas da SK, da SIM-P e da forma grave da COVID-19. Na primeira há grande liberação de IL-1, IL-2 e IL-6, enquanto nas outras duas são liberadas IL-10 e TNF-alfa. Já entre as duas últimas condições citadas, além do já mencionado, que a SIM-P acomete pacientes previamente hígidos e a forma grave da COVID-19, pacientes com comorbidades pré-existentes, salienta-se que as quantidades circulantes de IL-10 e TNF-alfa são três ou mais vezes maiores na SIM-P do que na forma grave da COVID-19. Além disso, a baixa carga viral e a presença de equinócitos circulantes nos pacientes com SIM-P são putativos de que esta condição clínica possa ser de etiologia pós-virótica, ou seja, ocorra não diretamente pela agressão do SARS-CoV-2, diferentemente da forma grave da COVID-19 que cursa com alta carga viral ${ }^{30}$.

O diagnóstico da SIM-P é estabelecido pelos critérios propostos pelo Ministério da Saúde, conforme o Quadro 1, com base na definição de caso da OPAS/OMS (WHO/2019nCoV/MIS Children CRF/2020.2), validado pela Sociedade Brasileira de Pediatria, Sociedade Brasileira de Reumatologia, Sociedade Brasileira de Cardiologia e Instituto Evandro Chagas ${ }^{31,32}$. Desde agosto de 2020 tornou-se notificação nacional obrigatória ao Ministério da Saúde ${ }^{32}$.

O manejo destes casos deve ser individualizado, de acordo com a apresentação clínica dos órgãos envolvidos, e deve ser conduzido por uma equipe pediátrica multiprofissional, fundamental para o melhor prognóstico destes pacientes. O objetivo do tratamento é diminuir o estado inflamatório multissistêmico, reduzir as sequelas cardíacas e a mortalidade associada a estes $\operatorname{casos}^{28}$.

O tratamento pode ser feito segundo os protocolos padrão para SK, associados à presença de choque e necessidade de suporte em UTI pediátrica, com drogas vasoativas, imunomoduladores e anticoagulantes. A prescrição de imunoglobulina endovenosa (IGEV) deve ser considerada naqueles que preenchem critérios completos ou parciais para a SK, nos casos com apresentações moderadas e graves como a SAM e síndrome do choque tóxico. A metilprednisolona é o corticosteroide de escolha para os casos de SIM-P, e seu uso deve ser considerado, junto 
com a IGEV, podendo ser administrada em forma de pulsoterapia nos casos graves e refratários. Imunomoduladores como anakinra (Anti-IL1), não disponível no Brasil, canaquinumabe (anti-IL1) ou tocilizumabe (anti-IL6) são reservados apenas para casos que se mostrarem refratários ao tratamento com IGEV e pulsoterapia com metilprednisolona. Antiagregantes plaquetários, como o ácido acetilsalicílico, são indicados nos casos de SIM-P com aneurismas coronarianos e/ou plaquetose. Nos casos de SIM-P com evidência de trombose ou que apresentem disfunção ventricular, com fração de ejeção < 35\%, a enoxaparina deverá ser indicada e mantida por pelo menos duas semanas após a alta hospitalar ${ }^{28,31,32}$.

Em um estudo prospectivo, multicêntrico, observacional, em 19 unidades de terapia intensiva pediátricas brasileiras, com 79 pacientes, sendo 10 com SIM-P, com idade entre 1 mês e 19 anos, a COVID-19 apresentou baixa mortalidade e a idade inferior a um ano não foi associada a um pior prognóstico. Nos pacientes com SIM-P houve uma predominância no sexo masculino, sintomas gastroinstestinais, marcadores inflamatórios mais elevados e uma maior gravidade; apenas a presença de comorbidades e doenças crônicas foi um preditor independente de gravidade ${ }^{33}$.

O Instituto da Criança do Hospital das Clínicas da Faculdade de Medicina da Universidade de São Paulo (HCFMUSP) publicou recentemente os resultados de pacientes pediátricos confirma- dos com COVID-19 com ou sem SIM-P. Esse estudo incluiu 371 pacientes (idade inferior a 18 anos) com suspeita de infecção por SARS-CoV-2, sendo $18 \%$ confirmados por exames laboratoriais. A SIM-P foi diagnosticada em $9 \%$ dos pacientes, sendo associada a um espectro clínico agudo com alta taxa de mortalidade. As frequências de sintomas gastroinstestinais, SARS pediátrico, hipoxemia e hipotensão arterial foram significativamente maiores em pacientes com SIM-P assim como níveis de PCR, dímero $\mathrm{D}$, troponina $\mathrm{T}$ e ferritina. As manifestações gastrointestinais e hipoxemia foram fatores associados à mortalidade ${ }^{34}$.

\section{DOENÇAS REUMÁTICAS PEDIÁTRICAS E COVID-19}

As recomendações gerais quanto às atitudes preventivas, com relação à exposição ao SARS-CoV-2 nos pacientes com doenças reumáticas, são as mesmas daquelas para a população geral, ou seja, isolamento quando necessário, manutenção do distanciamento social, utilização de máscaras e hábitos de higiene das mãos, com lavagem com água e sabão sempre que possível ou, quando de sua impossibilidade, utilização de álcool gel 70\%.

Não há qualquer recomendação para que as crianças e adolescentes portadores de doenças reumáticas alterem o seu tratamento medicamentoso rotineiro em função da pandemia da COVID-19. É importante que se mantenham contatos periódicos entre estes pacientes e os reumatologistas pediátricos que os

QUADRO 1 Definição de caso preliminar da síndrome inflamatória multissistêmica pediátrica (SIM-P) potencialmente associada à "coronavírus disease 2019".

\section{DEFINIÇÃO}

\section{Casos que foram hospitalizados com:}

- Presença de febre elevada $\left(>38^{\circ} \mathrm{C}\right.$ ) e persistente ( $\geq 3$ dias) em crianças e adolescentes (até 19 anos de idade)

E

- Pelos menos dois dos seguintes sinais e/ou sintomas:

- Conjuntivite não purulenta ou lesão cutânea bilateral ou sinais de inflamação mucocutânea (oral, mãos ou pés)

- Hipotensão arterial ou choque

- Manifestações de disfunção miocárdica, pericardite, valvulite ou anormalidades coronarianas [incluindo achados do ecocardiograma ou elevação de troponina, ou N-terminal do peptídeo natriurético tipo B (NT-proBNP)]

- Evidência de coagulopatia (por TP, TTPa ou D-dímero elevados)

- Manifestações gastrointestinais agudas (diarreia, vômito ou dor abdominal)

E

- Marcadores de inflamação elevados (VHS, PCR ou procalcitonina, entre outros)

E

- Afastadas quaisquer outras causas de origem infecciosa e inflamatória, incluindo sepse bacteriana, síndromes de choque estafilocócico ou estreptocócico

$\mathbf{E}$

- Evidência da COVID-19 (biologia molecular, teste antigênico ou sorológico positivos) ou história de contato com caso de COVID-19

\section{- Comentários adicionais:}

- Podem ser incluídas crianças e adolescentes que preencherem os critérios completos ou parciais para a síndrome de Kawasaki ou síndrome do choque tóxico

- Os profissionais de saúde devem considerar a possibilidade de SIM-P em qualquer morte pediátrica característica com evidência de infecção por SARS-CoV-2

TP = tempo de protrombina; TTPa = tempo de tromboplastina parcial ativada; VHS = velocidade de hemossedimentação; PCR = proteína C-reativa . Fonte: Safadi MAP, Silva CA. Notificação obrigatória no Ministério da Saúde dos casos de síndrome inflamatória multissistêmica pediátrica (SIM-P) potencialmente associada à COVID-1932. 
acompanham, propiciando muitas vezes métodos alternativos às consultas presenciais, através de teleconsultas ou por outros meios possíveis de comunicação, para que este acompanhamento possa se manter o mais efetivo possível. Em recente publicação com pacientes pediátricos com doenças reumáticas, foi ressaltada a importância da comunicação durante todo o processo de tratamento na pandemia. Alguns pacientes interromperam o tratamento por conta própria, por questões sociais, insegurança, medo, ansiedade ou por acreditar que os medicamentos imunossupressores representariam um risco para a COVID-19. Outros perderam o acompanhamento por restrições impostas pelos próprios hospitais, que os impediam de ter acesso aos cuidados de saúde ${ }^{35}$.

Em recente publicação de um estudo de coorte multicêntrico, retrospectivo, observacional, em adultos, realizado na Espanha, pacientes hospitalizados pela COVID-19 confirmados por PCR foram pareados entre grupos controle e outros dois grupos de pacientes com doenças reumáticas (DR) pré-existentes. Um dos grupos foi constituído por pacientes com artrites inflamatórias crônicas - DRAI (principalmente artrite reumatoide, artrite psoriásica, espondiloartropatias) - e outro por doenças do tecido conectivo - DRTC (principalmente lúpus eritematoso sistêmico, síndrome de Sjögren, esclerose sistêmica, vasculites, polimialgia reumática). 0 objetivo foi avaliar como as condições inflamatórias pré-existentes ou o uso prévio de terapia imunossupressora influenciariam nos desfechos finais. Os autores concluíram que: (1) o risco de COVID-19 grave foi maior no grupo com DR do que no grupo controle $(31,6 \%$ vs. $28,1 \%$, respectivamente, RR 1.13); (2) associação independente entre DRTC, idade, sexo masculino relacionados com risco aumentado para a COVID-19 grave; (3) por ser um grupo muito heterogêneo de DR, subdividiu-se a análise estatística demonstrando que os grupos de DRAI e DRTC apresentaram diferentes riscos para a COVID-19 grave, sendo maior neste último; (4) dentre o grupo de DRTC não se pode descartar a possibilidade de haver diferentes riscos específicos para cada uma das doenças; (5) idade elevada e ter DRTC foram os maiores fatores de riscos para pacientes com DR desenvolverem formas graves da COVID-19 ${ }^{36}$. Por não termos, até o presente momento, estudos específicos em reumatologia pediátrica que avaliassem as formas graves da COVID-19 e suas relações com as doenças reumáticas na infância, provavelmente poderemos supor, de maneira semelhante, que os achados do citado estudo possam ser compatíveis com crianças e adolescentes portadoras de doenças reumáticas.

O LES, considerado um protótipo das doenças autoimunes, talvez tenha em seus portadores uma maior predisposição para SARS-CoV-2 por ser associado a um curso de doença mais exacerbada, devido à hipometilação ACE-2 e sua superexpressã $0^{37}$.

Em algumas situações o LESJ pode se apresentar com formas multissistêmicas fulminantes, embora a maioria tenha apresentação insidiosa. Esses pacientes geralmente têm considerável envolvimento renal e do sistema nervoso central, características pouco observadas nos casos de SIM-P ${ }^{38}$. Lesões de pele como máculas violáceas, "rash" livedoide e púrpura são descritas em pacientes com COVID-19; algumas delas são semelhantes às ma- nifestações cutâneas de vasculite por IgA e manifestações sistêmicas com marcadores inflamatórios, como na poliarterite nodosa ${ }^{39}$.

Com relação aos pacientes com doenças autoinflamatórias, em um estudo recente não foram detectadas infecções secundárias ou risco de formas graves da COVID-19 naqueles que estavam em tratamento biológico e/ou terapia com colchicina ${ }^{40}$.

Outra ligação entre o campo da reumatologia e a pandemia atual são os medicamentos disponíveis no arsenal terapêutico reumatológico. Os estudos disponíveis indicam que as doenças reumáticas e os medicamentos imunossupressores utilizados em seu tratamento não representam um risco para a COVID-19.

Foram incluídos no tratamento da COVID-19 principalmente aqueles utilizados quando da iminência de se considerar situações de hiperinflamação decorrentes da ação do SARS-CoV-2. Quando deparados com a possibilidade de liberação maciça de citocinas inflamatórias, muitos medicamentos imunomoduladores podem ser utilizados na tentativa de se evitar o catastrofismo causado por estas proteínas. Estas drogas somente poderão ser utilizadas quando as condições destes pacientes envolverem uma piora clinicoevolutiva, com avaliação caso a caso ${ }^{41}$.

1. Inibidores de IL-6: como tocilizumabe, baseado em sua ampla utilização na reumatologia pediátrica (AIJ, esclerose sistêmica, vasculites) é também usado na SIM-P; outras drogas desta categoria, tais como o sarilumabe e o siltuximab, já foram utilizadas em ensaios clínicos na COVID-1941.

2. Inibidores de IL-1: como anakinra, também utilizado na reumatologia pediátrica ante a SAM, e na síndrome de "tempestade de citocinas", induzida por agentes infecciosos e por tumores. Na COVID-19 tem sido utilizada em protocolos clínicos de pacientes graves em UTI ${ }^{41}$.

3. Glicocorticoides: embora seja contraindicado nas fases iniciais da COVID-19, existem várias evidências de seu uso nas fases críticas da doença em adultos em UTI atenuando a imunodesregulação; contudo, sempre se deve contrabalançar esta ação, com seu efeito inibidor da resposta imune necessária para inibir a replicação viral, bem como o risco de infecções oportunistas ${ }^{41}$.

4. Imunoglobulina endovenosa: amplamente utilizada na reumatologia pediátrica, como na SK, e esporadicamente em algumas outras patologias; na SIM-P é uma escolha a ser feita, com ou sem a combinação com corticoesteroides ${ }^{41}$.

5. Inibidores da JAK: não se conhece seu uso fora de ensaios clínicos em pouquíssimos casos. Sabe-se que o baricitinib possui um alerta no potencial para provocar tromboses, assim sendo, não se sabe se seu efeito possa causar piora dos fenômenos tromboembólicos na COVID-1941.

6. Outros imunossupressores: como tacrolimus, micofenolato, utilizados no LES e em transplante de órgãos sólidos, não demonstraram efetividade nos pouquíssimos ensaios clínicos utilizados ${ }^{41}$.

Outro medicamento também utilizado na reumatologia, a hidroxicloroquina foi tentado como inibidor de crescimento viral e por sua ação imunomoduladora da inflamação, mas que 
se mostrou ineficaz em estudos clínicos bem conduzidos ${ }^{42}$. Promessa mais recente, a colchicina parece ter reduzido o tempo de necessidade de utilização de oxigênio e consequente tempo de permanência hospitalar de pacientes com formas moderadas da COVID-19 $9^{43}$.

\section{CONSIDERAÇÕES FINAIS}

Os reumatologistas pediátricos são agora confrontados diariamente com pacientes e familiares solicitando informações sobre como proceder em relação às consultas agendadas, visitas de infusão, bem como questionados se as mudanças de medicamentos ou a sua suspensão devam ser consideradas, devido ao possível aumento do risco de suscetibilidade às infecções secundárias decorrentes das próprias doenças e dos tratamentos imunossupressores. Os estudos disponíveis até o momento indicam que as doenças reumáticas e os medicamentos utilizados em seu tratamento não representam um risco para a COVID-19.

Os reumatologistas pediátricos estão familiarizados com o tratamento da COVID-19, desde as suas formas leves até as mais graves, devido às características inflamatórias que mimetizam as doenças reumáticas na possível patogênese, nas manifestações clínicas e achados laboratoriais. Além do mais, os medicamentos utilizados nos tratamentos das formas graves da COVID-19 já são amplamente conhecidos e habitualmente empregados na prática diária do reumatologista.

Até o momento, todos permanecemos com muitas incertezas diante de uma nova doença que é desafiante para todos os médicos e pesquisadores, mas que, ao mesmo tempo, instiga que novos caminhos sejam desvendados em sua patogenia, diagnóstico e tratamento, ansiando para que uma vacina eficiente esteja ao alcance de todos no mais breve tempo possível.

\section{Referências}

1. Dong Y, Mo X, Hu Y, Qi X, Jiang F, Jiang Z, et al. Epidemiology of COVID-19 among children in China. Pediatrics. 2020;145:e20200702. https://doi. org/10.1542/peds.2020-0702.

2. CDC COVID-19 Response Team. Coronavirus disease 2019 in children ---United States, February 12---April 2, 2020. MMWR Morb Mortal Wkly Rep. 2020;69:422-6. https://doi.org/10.15585/mmwr.mm6914e4.

3. Lu X, Zhang L, Du H, Zhang J, Li YY, Qu J, et al. SARS-CoV-2 Infection in Children. N Engl J Med. 2020. https://doi.org/10.1056/NEJMc2005073.

4. Wu Z, McGoogan JM. Characteristics of and Important Lessons from the Coronavirus Disease 2019 (COVID-19) Outbreak in China: Summary of a Report of 72314 Cases from the Chinese Center for Disease Control and Prevention [published online ahead of print, 2020 Feb 24]. JAMA. 2020;10.1001/ jama.2020.2648. https://doi.org/10.1001/jama.2020.2648.

5. Tagarro A, Epalza C, Santos M, Sanz-Santaeufemia FJ, Otheo E, Moraleda C, et al. Screening and severity of coronavirus disease 2019 (COVID-19) in children in Madrid, Spain. JAMA Pediatr. 2020:e201346 [Epub ahead of print]. https://doi.org/10.1001/jamapediatrics.2020.1346.

6. Zachariah P, Johnson CL, Halabi KC, Ahn D, Sen Al, Fischer A, et al. Epidemiology, clinical features, and disease severity in patients with coronavirus disease 2019 (COVID-19) in a children's hospital in New York City, New York. JAMA Pediatr. 2020:e202430 [Epub ahead of print]. https://doi.org/10.1001/ jamapediatrics.2020.2430.

7. Zhang H, Penninger JM, Li Y, Zhong N, Slutsky AS. Angiotensin-converting enzyme 2 (ACE2) as a SARS-CoV-2 receptor: molecular mechanisms and potential therapeutic target. Intensive Care Med. 2020;46:586-90. https://doi. org/10.1007/s00134-020-05985-9.

8. Rudolph M, McArthur MA, Barnes RS, Magder LS, Chen WH, Sztein MB. Differences between pediatric and adult $T$ cell responses to in vitro staphylococcal enterotoxin B stimulation. Front Immunol. 2018;9:498. https://doi. org/10.3389/fimmu.2018.00498.

9. Sun P, Lu X, Xu C, Sun W, Pan B. Understanding of COVID-19 based on current evidence. J Med Virol. 2020;92:548-51. https://doi.org/10.1002/jmv.25722.

10. Cyranoski D. Why children avoid the worst coronavirus complications might lie in their arteries. Nature. 2020;582(7812):324-325. https://doi. org/10.1038/d41586-020-01692-z.

11. Nickbakhsh S, Mair C, Matthews L, Reeve R, Johnson PCD, Thorburn F, et al. Virus-virus interactions impact the population dynamics of infuenza and the common cold. Proc Natl Acad Sci USA.2019. https://doi.org/10.1073/ pnas.1911083116.

12. Kleinnijenhuis J, Quintin J, Preijers F, Joosten LA, Ifrim DC, Saeed S, et al. Bacille Calmette-Guerin induces NOD2-dependent nonspecifc protection from reinfection via epigenetic reprogramming of monocytes. Proc Natl Acad Sci USA.2012; 109:17537-42. https://doi.org/10.1073/pnas.1202870109.
13. Miller A, Reandelar MJ, Fasciglione K, Roumenova V, Li Y, Otazu GH (2020) Correlation between universal BCG vaccination policy and reduced morbidity and mortality for COVID-19: an epidemiological study. medRxiv. https:// doi.org/10.1101/2020.03.24.20042937.

14. Ladhani SN, Amin-Chowdhury Z, Amirthalingam G, Demirjian A, Ramsay ME. Prioritising paediatric surveillance during the COVID-19 pandemic. Arch Dis Child. 2020 [Ahead of print]. https://doi.org/10.1136/archdischild-2020-319363.

15. Yonker LM, Neilan AM, Bartsch Y, Patel AB, Regan J, Arya P, et al. Pediatric SARS-CoV-2: Clinical Presentation, Infectivity, and Immune Responses, The Journal of Pediatrics (2020), doi: https://doi.org/10.1016/ j.jpeds.2020.08.037.

16. Hoang A, Chorath K, Moreira A, Evans M, Burmeister-Morton F, Burmeister F, et al. COVID-19 in 7780 pediatric patients: A systematic review. EClinicalMedicine. 2020;24:100433. Published 2020 Jun 26. https://doi.org/10.1016/j. eclinm.2020.100433.

17. Vieira RSR, Aguiar EL, Evangelista NMA, Sarrubbo SAB, Verlangieri HAR, Otsuka M. Clinical Characteristics in Children and Adolescents with SARS-CoV-2 Infection: Experience in a highly complex Public Hospital in the city of Sao Paulo. MedRXiV, Jul. 2020. Disponivel em https://www.medrxiv.org/content/ medrxiv/early/2020/07/19/2020.06.22.20136994.full.pdf. https://doi.org/ 10.1101/2020.06.22.20136994.

18. Grasselli G, Zangrillo A, Zanella A, Antonelli M, Cabrini L, Castelli A et al. Baseline Characteristics and Outcomes of 1591 Patients Infected with SARS-CoV-2 Admitted to ICUs of the Lombardy Region, Italy [published online ahead of print, 2020 Apr 6]. JAMA. 2020;323(16):1574-81. https://doi. org/10.1001/jama.2020.5394.

19. Parri N, Lenge M, Buonsenso D. Coronavirus Infection in Pediatric Emergency Departments (CONFIDENCE) Research Group. Children with Covid-19 in Pediatric Emergency Departments in Italy. N Engl J Med. 2020;383(2):187-90. https://doi.org/10.1056/NEJMc2007617.

20. Stokes EK, Zambrano LD, Anderson KN, Marder EP, Raz KM, Felix SEB, et al. Coronavirus Disease 2019 Case Surveillance - United States. 2020. MMWR Morb Mortal Wkly Rep. 2020;69(24):759-65. https://doi.org/10.15585/ mmwr.mm6924e2.

21. Götzinger F, Santiago-García B, Noguera-Julián A, Lanaspa M, Lancella L, Carducci FIC et al. COVID-19 in children and adolescents in Europe: a multinational, multicentre cohort study. Lancet Child Adolesc Health. 2020;4(9):65361. https://doi.org/10.1016/S2352-4642(20)30177-2.

22. FIOCRUZ. Instituto Nacional de Saúde da Mulher, da Criança e do Adolescente Fernandes Figueira. COVID-19 e Saúde da Criança e do Adolescente. Ago., 2020. Disponível em: https://portaldeboaspraticas.iff.fiocruz.br/atencaocrianca/covid-19-saude-crianca-e-adolescente.

23. BRASIL. Ministério da Saúde. Definição de caso e notificação. 2020. Disponível em: https://coronavirus.saude.gov.br/index.php/definicao-de-caso-e-notificacao. 
24. Riphagen S, Gomez X, Gonzalez-Martinez C, Wilkinson N, Theocharis P. Hyperinflammatory shock in children during COVID-19 pandemic. Lancet. 2020;395(10237):1607-08. https://doi.org/10.1016/S0140-6736(20)31094-1.

25. Belhadjer Z, Méot M, Bajolle F, Khraiche D, Legendre A, Abakka S, et al. Acute heart failure in multisystem inflammatory syndrome in children (MIS-C) in the context of global SARS-CoV-2 pandemic. Circulation. 2020 [Epub ahead of print]. https://doi.org/10.1161/CIRCULATIONAHA.120.048360.

26. Feldstein LR, Rose EB, Horwitz SM, Collins JP, Newhams MM, Son MB, et al. Multisystem inflammatory syndrome in U.S. children and adolescents. N Engl J Med. 2020:NEJMoa2021680 [Epub ahead of print]. https://doi. org/10.1056/NEJMoa2021680.

27. CDC. Multisystem Inflammatory Syndrome in Children (MIS-C) Associated with Coronavirus Disease 2019 (COVID-19). Disponivel em: https:// emergency.cdc.gov/han/2020/ hano0432.asp?deliveryName=USCDC_511 DM28431. Acesso em julho de 2020.

28. Jiang L, Tang K, Levin M, Irfan O, Morris SK, Wilson K, et al. COVID-19 and multisystem inflammatory syndrome in children and adolescents [published online ahead of print, 2020 Aug 17]. Lancet Infect Dis. 2020;S14733099(20)30651-4. https://doi.org/10.1016/S1473-3099(20)30651-4.

29. Safadi MAP, Silva CA. The challenging and unpredictable spectrum of COVID-19 in children and adolescents. Rev Paul Pediatr. 2020. https://doi. org/10.1590/1984-0462/2020/38/2020192.

30. Diorio C, Henrickson SE, Vella LA, MC Nerney KO, Chase JM, Burudpakdee C, et. al. Multisystem inflammatory syndrome in children and COVID-19 are distinct presentations of SARS-CoV-2. J Clin Invest. 2020. https://doi. org/10.1172/JCl140970.

31. WHO. Multisystem inflammatory syndrome in children and adolescents with COVID-19. https://www.who.int/publications/i/ item/multisystem-inflammatory-syndrome-in-children-andadolescents-with-covid-19 (accessed July 16, 2020).

32. Safadi MAP, Silva CA. Notificação obrigatória no Ministério da Saúde dos casos de síndrome inflamatória multissistêmica pediátrica (SIM-P) potencialmente associada à COVID-19. Departamento Científico de Infectologia (2019-2021), de Reumatologia (2019-2021), de Cardiologia (2019-2021), de Terapia Intensiva (2019-2021), e de Emergência (2019-2021). Sociedade brasileira de Pediatria, Agosto de 2020.

33. Prata-Barbosa A, Lima-Setta F, Santos GRD, Lanziotti VS, Castro ERV, Souza DC, et al. Pediatric patients with COVID-19 admitted to intensive care units in Brazil: a prospective multicenter study [published online ahead of print, 2020 Aug 4]. J Pediatr (Rio J). 2020;S0021-7557(20)30192-3. https://doi. org/10.1016/j.jped.2020.07.002.
34. Pereira MFB, Litvinov N, Farhat SCL, Eisencraft AP, Gibelli MABC, Carvalho WB, et al. Severe clinical spectrum with high mortality in pediatric patients with COVID-19 and multisystem inflammatory syndrome. Clinics. 2020;75:e2209.

35. Koker O, Demirkan FG, Kayaalp G, Kakmak F, Tanatar A, Karadag SG, et al. Does immunosuppressive treatment entail an additional risk for children with rheumatic diseases? A survey-based study in the era of COVID-19 2020 Aug 2]. Reumatol Int. 2020;1-11. https://doi.org/10.1007/s00296-02004663-9.

36. Pablos JL, Galindo M, Carmona L, Lledó A, Retuerto M, Blanco R, et. al. Clinical outcomes of hospitalised patients with COVID-19 and chronic inflammatory and autoimmune rheumatic diseases: a multicentric matched cohort study. Ann Rheum Dis 2020;0:1-6. https://doi.org/10.1136/annrheumdis-2020-218296.

37. Sawalha AH, Zhao M, Coit P, Lu Q. Epigenetic dysregulation of ACE2 and interferon-regulated genes might suggest increased COVID-19 susceptibility and severity in lupus patients. Clin Immunol. 2020;215:108410. https://doi. org/10.1016/j.clim.2020.108410.

38. Batu ED, Özen S. Implications of COVID-19 in pediatric rheumatology. Rheumatol Int. 2020;40(8):1193-213. https://doi.org/10.1007/s00296-02004612-6.

39. Freeman EE, McMahon DE, Lipoff JB, Rosenbach M, Kovarik C, Desai SR, et al. The spectrum of COVID-19-associated dermatologic manifestations: An international registry of 716 patients from 31 countries [published online ahead of print, 2020 Jul 2]. J Am Acad Dermatol. 2020;S0190-9622(20)32126-5. https://doi.org/10.1016/j.jaad.2020.06.1016.

40. Haslak F, Yildiz M, Adrovic A, Sahin S, Koker O, Aliyeva A, et al. Management of childhood-onset autoinflammatory diseases during the COVID-19 pandemic. Rheumatol Int. 2020;40(9):1423-1431. https://doi.org/10.1007/ s00296-020-04645-x.

41. Dulek DE, Fuhlbrigge RC, Tribble AC, Connelly JA, Loi MM, El Chebib H, et al. Multidisciplinary Guidance Regarding the Use of Immunomodulatory Therapies for Acute COVID-19 in Pediatric Patients. Journal of the Pediatric Infectious Diseases Society, piaa098. https://doi.org/10.1093/jpids/piaa098.

42. Boulware DR, Pullen MF, Bangdiwala AS, Pastick KA, Lofgren SM, Okafor EC, et al. A Randomized Trial of Hydroxychloroquine as Postexposure Prophylaxis for Covid-19. The New England journal of medicine. 2020; 383(6):517-25. https://doi.org/10.1056/NEJMoa2016638.

43. Lopes MIF, Bonjorno LP, Giannini MC, Amaral NB, Benatti MN, Rezek UC, et al. Beneficial effects of colchicine for moderate to severe COVID-19: an interim analysis of a randomized, double-blinded, placebo controlled clinical trial. https://www.medrxiv.org/content/10.1101/2020.08.06.20169573v2.full.pdf. 